\title{
Hydrating softwood and hardwood samples using pure and modified supercritical carbon dioxide
}

\author{
Georgina Hammond ${ }^{1 *}$ (10 and Phil Cox ${ }^{2}$
}

\begin{abstract}
This article describes an in-progress research project that looks to investigate the use of supercritical carbon dioxide $\left(\mathrm{s} \mathrm{CO}_{2}\right)$ for the addition of water to historic and modern, softwood and hardwood samples. The experiments were carried out at $20 \mathrm{MPa}$ and $50^{\circ} \mathrm{C}$, the effects of co-solvent addition, methanol (MeOH), were examined. A three point bend test provided mechanical data for the wood samples treated with both pure and modified $\mathrm{scCO}_{2}$. All the wood samples, with only one exception, saw an increase in Modulus of Rupture (MOR) after being treated with $\mathrm{scCO}_{2}$. Thereby indicating an increased resistance to force in the treated samples. Diffuse Reflectance Infrared Fourier Transform (DRIFT) spectroscopy was performed to help deduce if any trends in the $\mathrm{OH} / \mathrm{CH}$ and $\mathrm{OH} / \mathrm{Cellulose}$ peak area ratios could be established with the nature of the treatment and the type of wood used. The development of this technique seeks to be relevant and safe for applications within modern conservation practices, where dry and fragile materials are prevalent.
\end{abstract}

Keywords: Supercritical fluids, Supercritical carbon dioxide, Co-solvent, Hardwood, Softwood, Mechanical testing, Three-point bend test, DRIFT spectroscopy, Conservation

\section{Background}

A supercritical fluid (SCF) can be defined as a substance that has a temperature and pressure greater than its critical temperature $\left(T_{c}\right)$ and critical pressure $\left(P_{c}\right)$ respectively [1]. At this critical point a vapour-liquid equilibrium can exist, the phenomena is clearly depicted in Fig. 1. SCFs have liquid-like densities that enable them to act as solvents, they also have gas-like viscosities and self-diffusivities higher than liquid solvents which can facilitate mass transfer and reaction rates [2]. Carbon dioxide $\left(\mathrm{CO}_{2}\right)$ is the most commonly used solvent in SCFs and is most applicable for uses within conservation. This is mainly due to being non-toxic at low concentrations, non-flammable, inexpensive, inert and recyclable properties. $\mathrm{CO}_{2}$ also holds a generally regarded as safe (GRAS) status [3] and is an environmentally friendly

\footnotetext{
*Correspondence: geh391@bham.ac.uk

${ }^{1}$ Department of Chemical Engineering, University of Birmingham, Edgbaston, Birmingham B15 2TT, UK

Full list of author information is available at the end of the article
}

substitute for other organic solvents. Notably, $\mathrm{CO}_{2}$ also has relatively low supercritical conditions: $\mathrm{T}_{\mathrm{c}}=31.1{ }^{\circ} \mathrm{C}$ and $\mathrm{P}_{\mathrm{c}}=7.38 \mathrm{MPa}$.

Due to $\mathrm{scCO}_{2}$ being a non-polar solvent it has a very poor solvating ability with highly polar water molecules. To overcome this problem $\mathrm{scCO}_{2}$ is generally modified with polar entrainers to improve its affinity with polar compounds. Different entrainers can be added to $\mathrm{CO}_{2}$ to aid different characteristics. However, methanol $(\mathrm{MeOH})$ or ethanol $(\mathrm{EtOH})$ are most commonly entrained to increase polarity because both have a relatively low molar mass and a critical temperature similar to that of $\mathrm{CO}_{2}[2,4]$.

Due to the high penetration ability of SCF solvents compared to that of liquids, SCF impregnation for the delivery of aqueous solutions e.g. biocides, into wood and wood composites has become an area of great interest, with developments into commercial scale practices [5]. $\mathrm{scCO}_{2}$ is able to overcome pit impermeability which poses a limitation to effective biocide treatment in heartwood [6]. It has been shown that SCF treatments are 


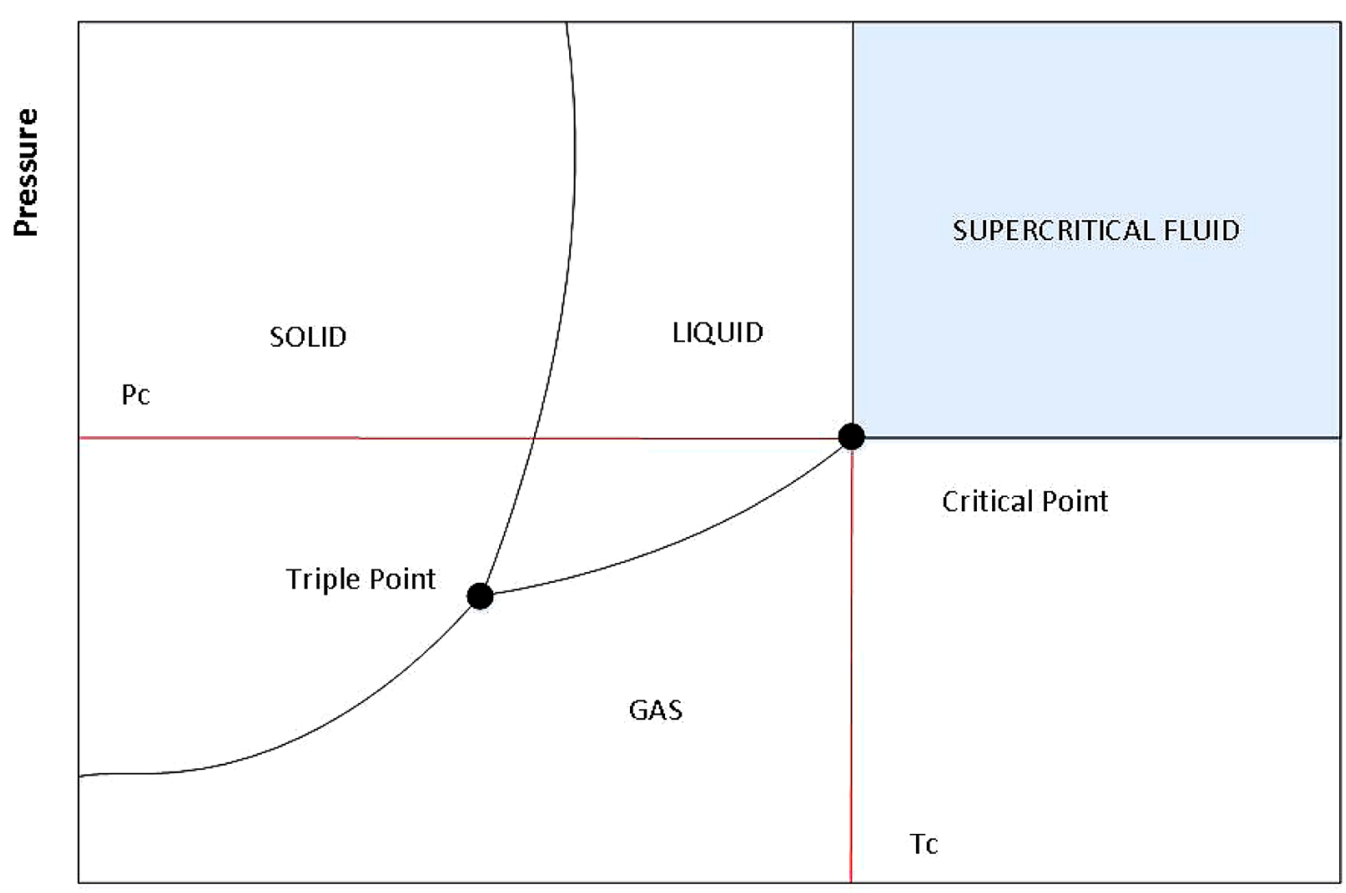

Temperature

Fig. 1 Generic phase diagram for supercritical fluids

able to completely impregnate Douglas-fir heartwood, which have previously been resistant to fluid treatments [7]. Although treatment length may vary, treatment conditions for SCF impregnation are normally standard for temperature and pressure. Oven temperature will vary between 40 and $50{ }^{\circ} \mathrm{C}$ depending on the presence of a cosolvent, and pressure may vary between 15 and $20 \mathrm{MPa}$ [5]. This region of conditions will ensure that the $\mathrm{scCO}_{2}$ solvent stream is at a high density in the critical region, thus facilitating high mass transfer [8]. Wood will not equilibrate instantaneously when being pressurised by a fluid, a pressure differential will occur between the surface of the wood and the interior [9]. The development of this differential is dependent on pressurisation, venting rates and the structural geometry of the wood [10, 11]. Precautions must therefore be taken when depressurising a SCF system to minimise any damage to the wood structure.

The application of $\mathrm{scCO}_{2}$ within art conservation has not been extensive, this is probably due to the high costs associated with the specialist equipment required for $\mathrm{scCO}_{2}$ and the relatively low research funding found in most conservation departments across the world. However, when $\mathrm{scCO}_{2}$ has been used in a conservation capacity the results have been very encouraging. Cleaning, including the removal of pesticides, and deacidification are two of the most widely investigated applications in conservation [12-14]. Kang et al. [15] who looked at pesticide reduction in wood artefacts, applied a $\mathrm{scCO}_{2}$ extraction treatment for $30 \mathrm{~min}$ at $45^{\circ} \mathrm{C}$ at $30 \mathrm{MPa}$, achieving $60 \%$ removal of dichlorodiphenyltrichloroethane (DDT). Tello [16] was able to treat fragile ethnographic materials with a $\mathrm{scCO}_{2}$ treatment at $40{ }^{\circ} \mathrm{C}$ at $35 \mathrm{MPa}$ for 3-7 $\mathrm{h}$, resulting in levels of chlorine containing compounds and heavy metal mercury all being reduced. From a conservation viewpoint, it is important to note that in all of these studies $\mathrm{ScCO}_{2}$ was used as a solvent stream for the extraction of pesticides without harming fragile materials.

It is proposed here that the hydration of historic wood, via a SCF solvent stream, may be considered amongst the techniques suitable for use within modern conservation practices. The aim of the work described here is to evaluate the addition of water using $\mathrm{scCO}_{2}$ with and without the use of a co-solvent, $\mathrm{MeOH}$. The ability of the supercritical treatment to increase the stabilised moisture content of the test sample whilst also increasing the wood samples MOR, or bending strength, will be evaluated. Wood has been chosen as a test sample because it is readily available in both modern and historic forms, it is also a material that is common within museum collections and it can be easily modelled. 


\section{Methods}

\section{Materials}

Modern hardwood samples were collected from SL Hardwoods (Croydon, UK), whilst historical hard and softwood samples were collected from Oxford Violins (Oxford, UK) and Oxford Wood Recycling Ltd (Abingdon, UK). All the wood samples were kept under ambient conditions until they underwent oven drying. $\mathrm{CO}_{2}$ (liquid withdrawal) was supplied by Air Liquide (Paris, France). Absolute methanol (99.9\% pure) was supplied by Fisher Scientific (Loughborough, UK) and was of Analar grade.

\section{Wood preparation and initial characterisation}

Wood samples were characterised into historic $(H)$ (>100 years since being cut) and modern $(M)(<100$ years since being cut) and then sub-categorised into hardwoods and softwoods. Hardwood species included Maple, White Oak, Red Oak, Zebrano and Keruing. Scots Pine was the only softwood species used. Samples were cut with a precision high-speed table circular saw into rectangular pieces (length $=0.06 \mathrm{~m}$, width $=0.01 \mathrm{~m}$, height $=0.01 \mathrm{~m}$ ). These samples were lightly sanded to remove any debris from cutting.
The initial moisture content of the wood was measured by drying the samples at $70{ }^{\circ} \mathrm{C}$ in the presence of anhydrous sodium sulphate in an oven to a constant mass, and comparing to the original mass. The initial moisture content on average for the historic woods was found to be $7.7 \% \mathrm{w} / \mathrm{w}$ and for the modern woods $9.0 \% \mathrm{w} / \mathrm{w}$. After being oven dried, two coats of epoxy resin were painted on the square ends of the samples and re-weighed.

\section{Supercritical hydration}

A schematic illustration of the supercritical hydration rig is shown in Fig. 2. Two of the wood samples were positioned linearly in the centre of the $25 \mathrm{ml}$ cell and stainless steel mesh was placed at either end of the cell. Tissue saturated with distilled water was added into the hydration cell and sealed, the oven was then heated to $50{ }^{\circ} \mathrm{C}$. For the experiments that had the addition of a co-solvent, prepared $\mathrm{MeOH}$ solutions of stated concentrations $(2.5 \mathrm{~mol} \%$ and $5.0 \mathrm{~mol} \%)$ were added to the tissue at this point. $\mathrm{CO}_{2}$ was pulled from the supply cylinder via a dessicator tube before it was cooled to a liquid state (to allow for efficient pumping) and compressed to the desired pressure by a Thar high pressure P-series

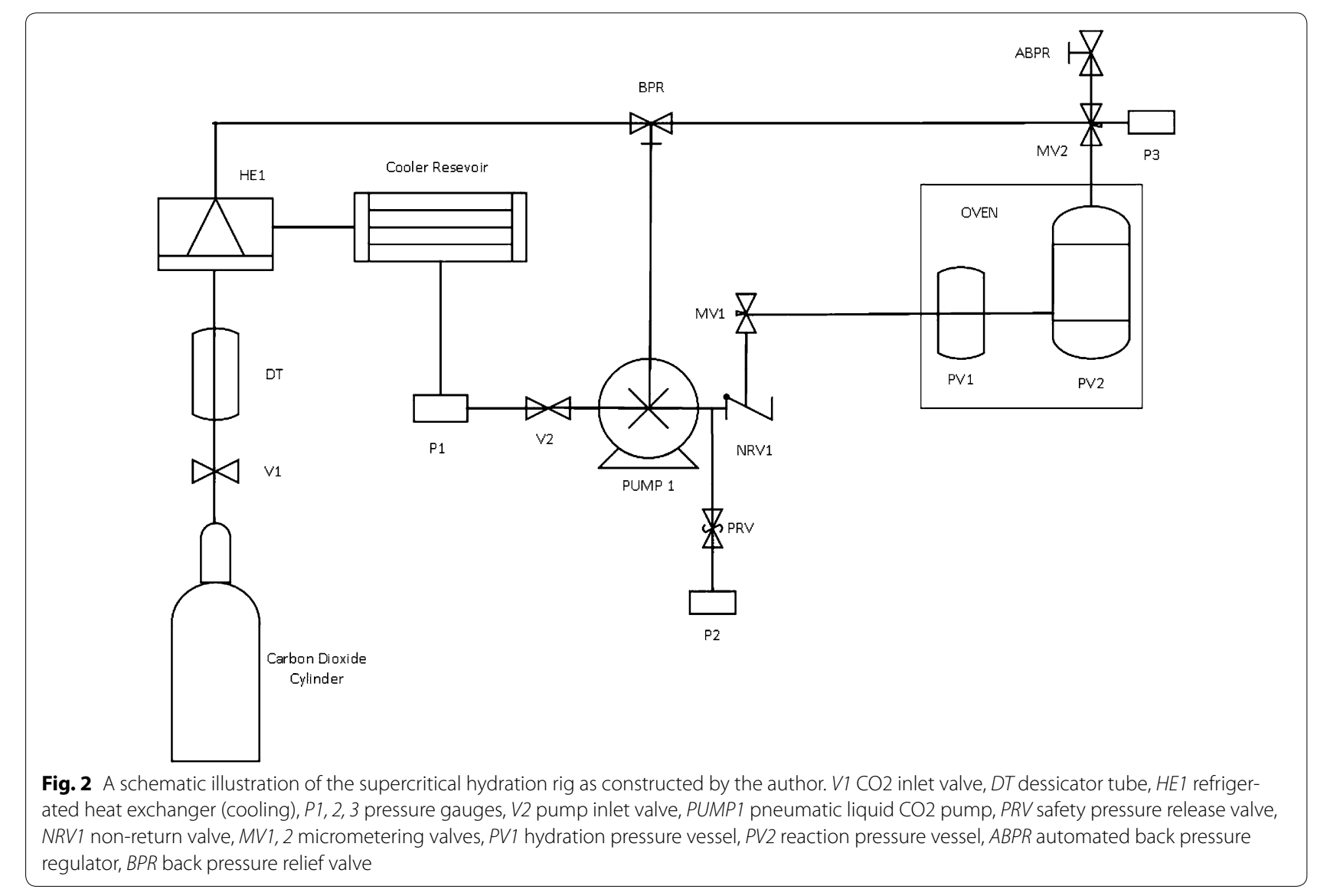


pump. Once the desired temperature $\left(50{ }^{\circ} \mathrm{C}\right)$ and pressure $(20 \mathrm{MPa})$ had been achieved the entry valve (MV1) into the oven was opened and the system was held at static pressure for $45 \mathrm{~min}$. The pressure was controlled and monitored throughout the experiment using the computer (Thar Technologies Inc., Pittsburgh, PA, USA), whilst the oven temperature was monitored using a temperature probe (K Type thermocouple input probe) and digital monitor (TC305K Digital handheld thermometer). At the end of every experiment the pump was turned off and the entry value into the oven (MV2) was closed whilst the exit value (MV2) was opened into a fume hood to allow for slow depressurisation over $45 \mathrm{~min}$. For the experimental conditions discussed in this paper to remain constant, it was ensured that the system was in the single phase, supercritical region for all treatment procedures. Phase diagrams and Table 1 below were consulted to ensure the correct conditions were maintained.

The percentage change in mass of each sample was calculated using the following equation:

$$
\frac{(M 2-M 1)}{M 1} \times 100
$$

where $\mathrm{M} 1$ is the oven dried mass and M2 is the mass post treatment. This value was known as the normalised moisture content (NMC) of the wood sample, the value is said to be 'normalised' because as a percentage change the effects of varying sample size have been removed. This calculation was carried out immediately after depressurisation, continuing at regular time intervals until a constant mass was reached. For the duration of the time post-SCF treatment the samples were kept in individual, nitrogen sealed containers. All experiments (each involving two wood samples) were carried out in quintuplets. The mean values from each of the individual experiments were combined and an overall mean \pm one standard error of the mean calculated.

The effects of the experimental conditions on the overall mean moisture contents were statistically examined.

\begin{tabular}{lcc}
$\begin{array}{l}\text { Table } \mathbf{1} \text { The critical } \\
\text { scCO }\end{array} \mathbf{2}-\mathbf{M e O H}$ system \\
\hline $\mathbf{M e O H}$ mole fraction & $\mathbf{T}_{\mathbf{c}}\left({ }^{\circ} \mathbf{C}\right)$ & $\mathbf{P}_{\mathbf{c}}(\mathbf{M P a})$ \\
\hline 0.00 & 31.1 & 7.4 \\
0.07 & 51.1 & 10.5 \\
0.12 & 64.9 & 12.2 \\
0.20 & 85.9 & 14.4 \\
0.36 & 124.4 & 16.5 \\
1.00 & 240.0 & 8.0 \\
\hline
\end{tabular}

The critical temperatures and pressures increase with increasing $\mathrm{MeOH}$ concentration
The Student $t$ test was used to examine for differences where experiments were paired for comparison. The null hypothesis stated that the SCF treatment with either $\mathrm{scCO}_{2 \text { (PURE) }}$ or modified $\mathrm{scCO}_{2}$ has no effect on the moisture content of an oven-dried wood sample. The chosen level of significance, $\alpha$, for all tests was 0.05 .

\section{Three point bent test}

A simple three-point bend test was used to determine Young's modulus (E) of different wood samples. Bending strength or Modulus of Rupture (MOR), can also be determined as a function of E. Each of the eight wood types were collected to test the possible adverse effects of the SCF treatments on the mechanical properties of the wood. Treated and untreated samples were selected in order to be able to make direct comparisons between the mechanical properties. For each treatment three samples of wood were selected, and the three-point bend test was carried out in triplicate. The untreated wood was oven-dried to a constant mass and kept in sealed nitrogen containers until use. The testing was carried out using a Bose Electroforce 5500 mechanical tester (Bose/TA Instruments, Minnesota, USA) and WinTest 7 software (Bose) at the University of Birmingham.

The width (a) and height (b) of the wood samples were measured and the samples were placed in the apparatus with the height of the wood orientated vertically. The distance (L) between the two supports was measured. A force (P) was applied up to $200 \mathrm{~N}$ over $40 \mathrm{~s}$. To make accurate assumptions about the samples elastic properties it is important that the wood does not become permanently deformed i.e. the beam does not return to its original shape after deflection. The force applied was therefore added incrementally and could be stopped at any time. For each treatment type, force (P) and displacement $(w)$ values were recorded for the three wood samples, two with the grain and one against the grain. It was important to carry out the three-point bend test on the samples of wood both with and against the grain, the triplicate values were averaged to give a mean value representative of the woods structure. Force, displacement curves were plotted using the WinTest 7 software. A gradient $(\delta P / \delta w)$ was recorded in the elastic region of the graph for each test.

Young's modulus (E) can be found using the following equation, where $(\delta \mathrm{P} / \delta w)$ is the gradient and I is the second moment of area:

$$
E=\frac{\left(\frac{\delta P}{\delta w}\right) L^{3}}{(48 I)}
$$


The strength (MOR) of the wood can be found using the below, where $m$ is equal to the gradient of the graph and $g$ is the gravitational constant [17]:

$$
M O R=\frac{3 m g L}{2 a b^{3}}
$$

Using these equations values for $\mathrm{E}$ and strength could be collected for the different wood samples.

\section{Diffuse reflectance infrared fourier transform (DRIFT) spectroscopy}

This technique was carried out to see if in principle it could be possible to identify a degree of water content and other constituents of the wood. This would be with regards to a relative scale and with the limitation that these studies were carried out on the surface of the wood. Previous work by Pandey into the surface structure of hard and softwood, has shown this may be possible [18]. All spectroscopic analysis was carried out at Chiralabs Limited (Oxford, UK).

A study using DRIFT spectroscopy on twenty treated modern samples of wood was carried out, with some trends being identified. Five samples of four types of wood were tested; Maple, Red Oak, White Oak and Zebrano. Each sample was placed on the holder of a diffuse reflectance (DRIFT) optics attachment and presented such that a rough flat face was illuminated. DRIFT in comparison to other spectroscopic methods, namely NIR-Raman and Attenuated Total Reflection Fourier Transform Infrared Absorption (ATR-FTIR) spectroscopy, was found to give the most feature-rich spectra and was therefore deemed suitable for further analysis of wood samples. This technique can be applied to freshly sectioned portions of wood, either with or across the grain, allowing the probing of the internal levels of constituents compared to those on the established outer surfaces.

\section{Results and discussion}

Hydration with $\mathrm{scCO}_{2 \text { (PURE) }}$ and $\mathrm{scCO}_{2(\mathrm{CH} 3 \mathrm{OH})}$

As discussed in the introduction, when $\mathrm{scCO}_{2}$ is modified with a polar co-solvent, the solvating power of $\mathrm{scCO}_{2}$ with other polar compounds such as water, is significantly increased [19]. The increase in stabilised $\mathrm{NMC}$ with increasing quantities of $\mathrm{MeOH}$, shown here in Fig. 3, were therefore expected. Both historic and modern

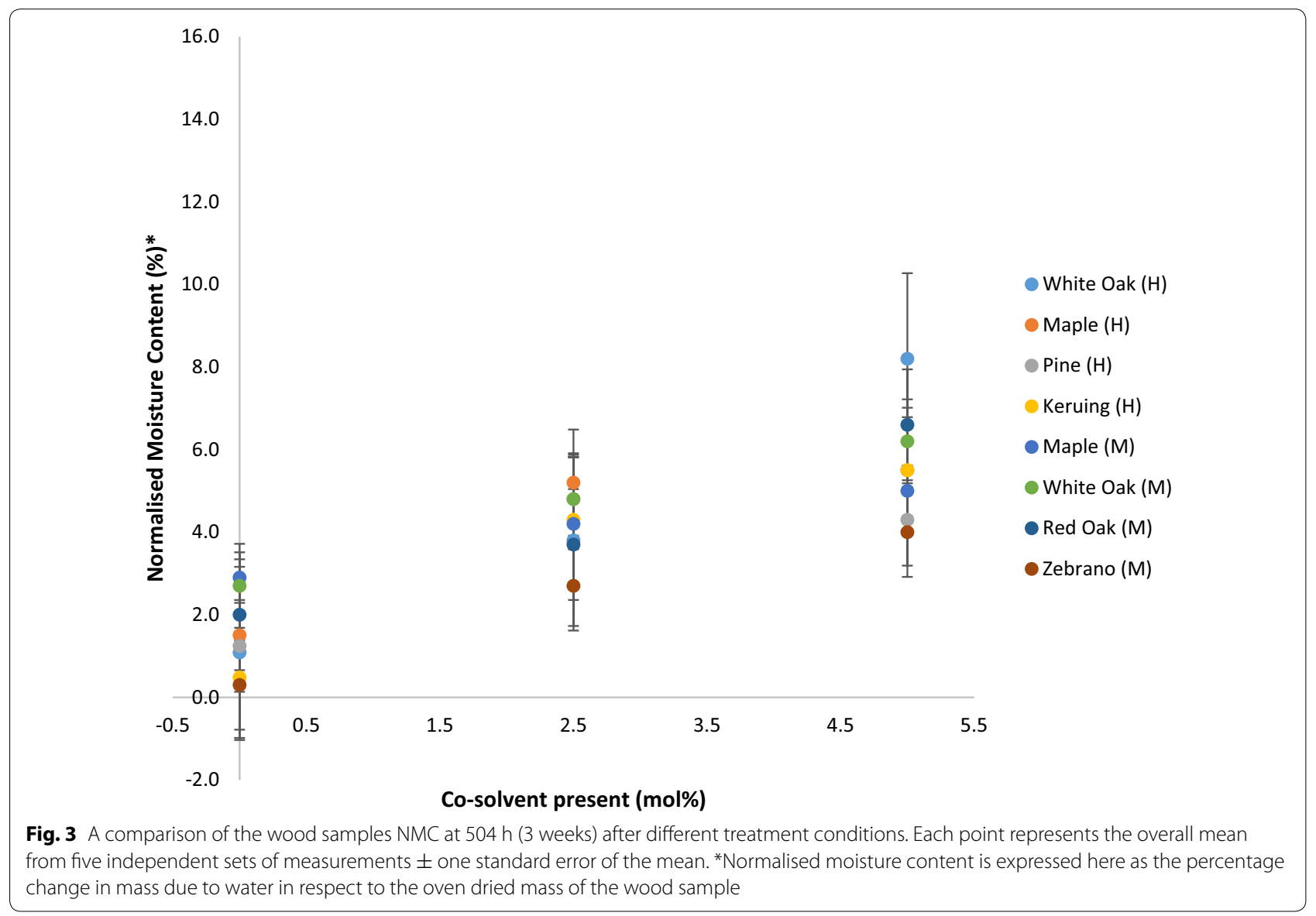


wood samples responded positively to the increased concentration of $\mathrm{MeOH}$ co-solvent. It should be noted, however that the woods treated with $\mathrm{scCO}_{2(\mathrm{PURE})}$ also showed increased moisture content post treatment. An average stabilised NMC (at $504 \mathrm{~h}$ ) of $\sim 1.5 \%$ for both the historic and modern wood samples was achieved. Thus, showing that hydration with unmodified $\mathrm{scCO}_{2}$ in the presence of water was possible, if very low. At $504 \mathrm{~h}$, or 3 weeks, all the wood samples had stabilised at a constant mass. Hydration profiles presented in this paper use data up to and including the $504 \mathrm{~h}$, but not after that time. However, all the samples where continually weighed at regular intervals over a 48 -week $(8064 \mathrm{~h})$ period and he data was recorded.

Hydration profiles for historic and modern wood samples treated with $\mathrm{scCO}_{2(\mathrm{PURE})}$ in the presence of water and modified $\mathrm{scCO}_{2}$ with $5.0 \% \mathrm{MeOH}$ are shown in Figs. 4 and 5. Again, the addition of $\mathrm{MeOH}$ can be seen to increase the overall NMC, importantly for $5.0 \mathrm{~mol} \%$ $\mathrm{MeOH}$ the stabilised NMC after $504 \mathrm{~h}$ for all woods was above $4 \%$. Statistically the treatment using $5.0 \mathrm{~mol} \%$ $\mathrm{MeOH}$ was shown to give the highest number of significant results, followed by $2.5 \mathrm{~mol} \% \mathrm{MeOH}$ and then $\mathrm{scCO}_{2 \text { (PURE). }}$
With conservation methods in mind and due to the variance in the wood samples age and physical properties, it is important to look at the samples performance post treatment, on an individual basis. Of the hardwoods, White Oak $(H / M)$, Red Oak $(M)$ and Maple $(H / M)$ seem to respond well to the SCF treatment, especially the Oak samples which consistently gained a high stabilised NMC. White Oak $(H)$ achieved the highest NMC at 8.2\% with $5.0 \mathrm{~mol} \%$ co-solvent, with Red Oak $(M)$ and Maple $(M)$ achieving $7.2 \%$ and $7.0 \%$ respectively. This suggests the treatment is suitable for both historic and modern wood samples even with the highest percentage co-solvent. White Oak $(H)$ and $\operatorname{Red}$ Oak $(M)$ gave significant results at 0,168 and $504 \mathrm{~h}$ when treated with $5.0 \mathrm{~mol} \%$ $\mathrm{MeOH}$. The mechanical analysis carried out will assess whether the SCF treatment is in turn adversely affecting the integrity of the wood samples.

If we look at the historic wood sample set although Maple $(H)$ and White Oak $(H)$ consistently achieved high levels of stabilised NMC, Scots Pine $(H)$ and Keruing $(H)$ achieved some of the lowest NMC out of the whole sample set. It should be said that the Scots Pine $(H)$ sample was the most visibly aged of the historic wood samples, and it is therefore unsurprising that it achieved low levels

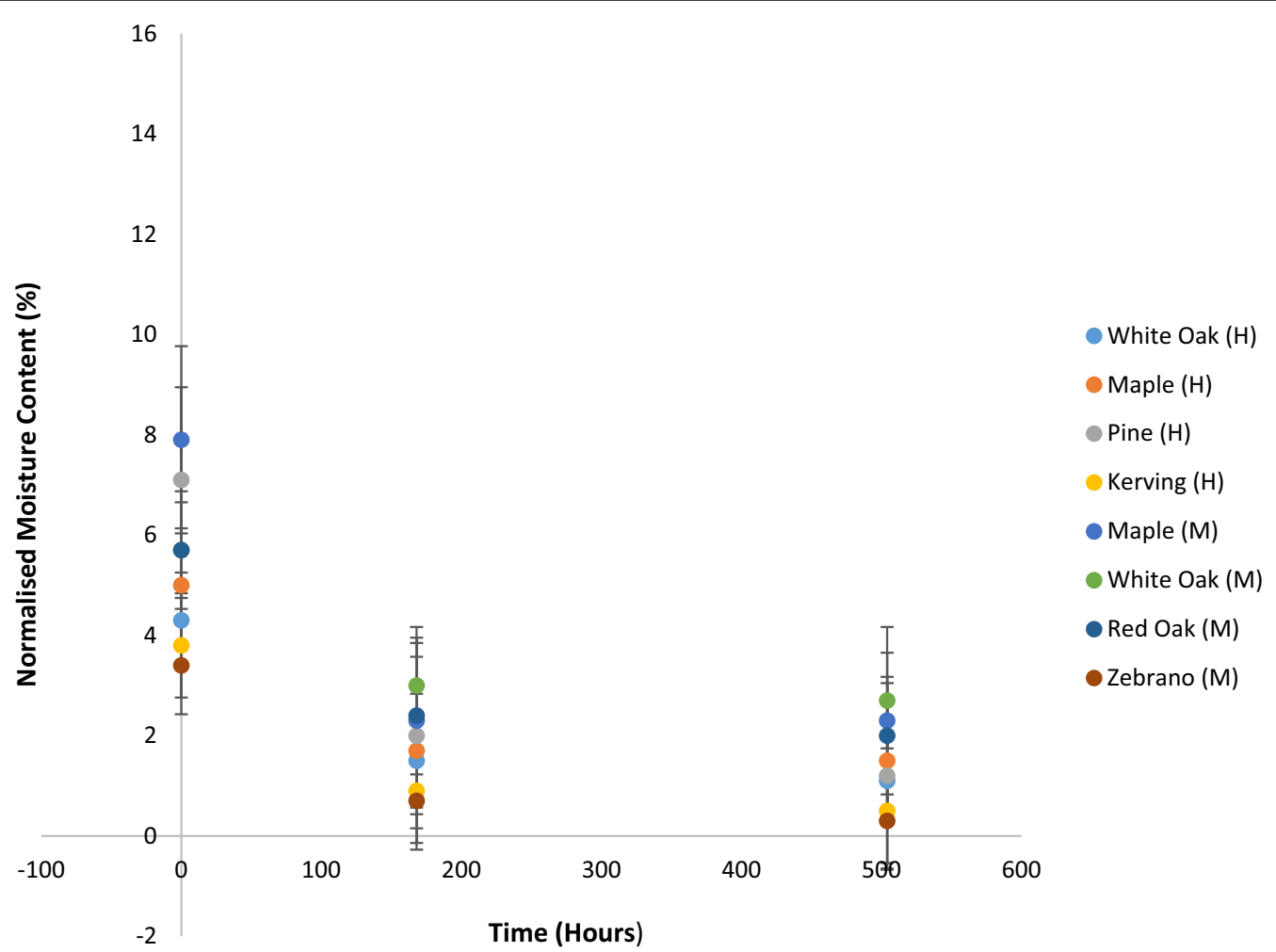

Fig. 4 The normalised moisture content of wood samples taken at 0 h, $168 \mathrm{~h}$ (1 week) and $504 \mathrm{~h}$ ( 3 weeks). The wood samples have been treated with $\mathrm{scCO}_{2(\text { PURE) }}$ in the presence of water. Each point represents the overall mean from five independent sets of measurements \pm one standard error of the mean 


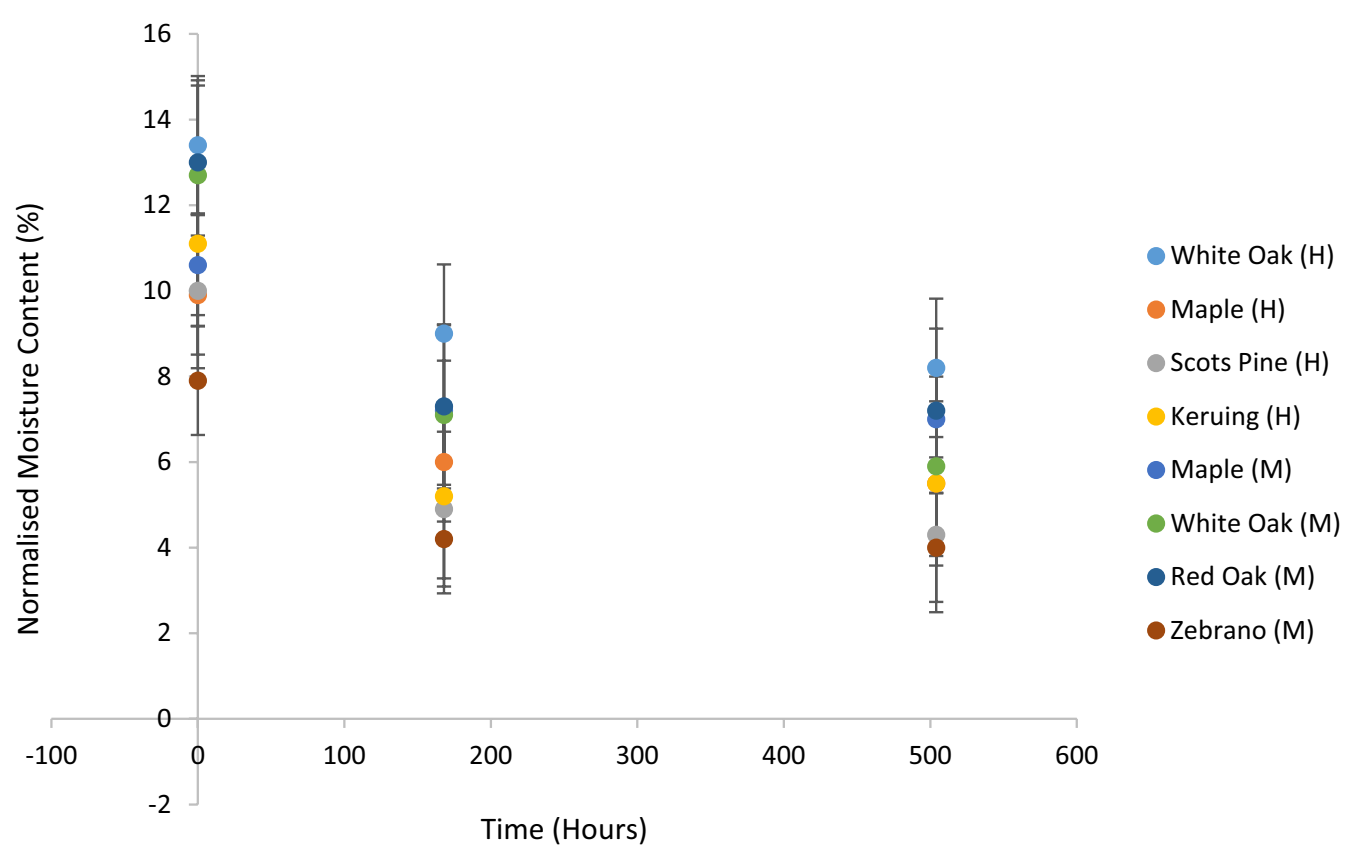

Fig. 5 The normalised moisture content of wood samples taken at 0 h, $168 \mathrm{~h}$ ( 1 week) and $504 \mathrm{~h}$ (3 weeks).The wood samples have been treated with $\mathrm{scCO}_{2(\mathrm{MeOH})}$ in the presence of $\mathrm{H}_{2} \mathrm{O}, \mathrm{MeOH}$ has a concentration of $5.0 \mathrm{~mol} \%$. Each point represents the overall mean from five independent sets of measurements \pm one standard error of the mean

of NMC. It is most likely that abiotic deterioration has occurred over $100+$ years causing some depolymerisation and breakdown of the woody fibres. As a tropical hardwood, Keruing $(H)$, may have a greater natural resistance to deteriorative processes as it is more durable than the softwood, Scots Pine $(H)$. Although it is unknown whether the historic wood samples were taken from the heartwood or sapwood of the tree, it is interesting that White Oak $(H)$ achieved consistently high levels of NMC alongside White Oak $(M)$. White Oak is known to be a species whose heartwood is naturally resistant to decay, whereas pine species are known to be naturally only very slightly or completely non-resistant to decay [20].

Additionally, the modern tropical hardwood Zebrano $(M)$ gave no significant results at $504 \mathrm{~h}$ with any of the supercritical treatment types. Due to this low ability to retain increased levels of moisture, it could also be suggested that Zebrano $(M)$ is one of the wood samples that is not suitable for SCF impregnation of this type. Here it is interesting to look at the lignin contents of the different wood species. Softwoods are known to consist of $26-32 \%$ lignin and tropical hardwoods around 30\% lignin, whilst temperate hardwoods are composed of approximately 20-25\% lignin [21]. The lower composition of lignin found in hardwood could be a factor in the woods ability to absorb water. If there is less lignin to bind the hemicellulose and cellulose together, then there may be a higher availability of hydroxyl sites on the cellulose chain free to absorb water via hydrogen bonding. Therefore, assumptions can be made between the inconsistent hydration results of both Scots Pine $(H)$ and Zebrano $(M)$ and the lower percentage of lignin present in their softwood and tropical hardwood structures. Consequently, there seems to be a negative correlation between the percentage composition of lignin known to be in the wood structure and the stabilised NMC achieved by the treated wood samples, as indicated by the hydration profiles for both Zebrano $(M)$ and Scots Pine $(H)$.

\section{Three-point bend test}

The pre-treatment strengths of the individual wood samples were as expected [22]; the tropical hardwoods Zebrano $(M)$ and Keruing $(H)$ are shown to be the strongest samples, followed by the hardwoods Maple $(M / H)$ and White Oak $(M / H)$ and Red Oak $(H)$, and finally Scots Pine $(H)$, a softwood. Scots Pine $(H)$ is by far the weakest at approximately $100 \mathrm{MPa}$, whilst Zebrano is the strongest wood of the samples, with a pre-treatment strength of approximately $800 \mathrm{MPa}$, of the hardwoods Maple is shown to be slightly stronger than White Oak. The pretreatment strength values show that the species of the wood is more of an influencing factor on strength than the age of the wood (Table 2). However, it is important to note that of the species that have comparative historic 
Table 2 A table to show oven-dried wood samples in decreasing order of mean strength prior to treatment with $\mathrm{SCCO}_{2(\mathrm{PURE})}$ and $\mathrm{sCCO}_{2(\mathrm{MeOH})}$

\begin{tabular}{lll}
\hline Wood species & MOR of samples (MPa) & Wood type \\
\hline Zebrano $(M)$ & 791 & Tropical hardwood \\
Keruing $(H)$ & 718 & Hardwood \\
Maple $(M)$ & 640 & \\
Maple $(H)$ & 634 & \\
White Oak $(M)$ & 528 & \\
Red Oak $(M)$ & 519 & Softwood \\
White Oak $(H)$ & 514 & \\
Scots Pine $(H)$ & 110 &
\end{tabular}

Strength values have been stated to an accuracy of 3 significant figures

and modern samples e.g. Maple, the modern sample is always stronger than the historic sample. Clearly the historic wood samples have been adversely affected by degradation processes that have damaged the structural integrity of the wood samples [23].

Given the previous results for mechanical testing of wood treated with SCF's [7], it seems significant that the all the samples tested in this study showed an increased MOR or bending strength post treatment both with $\mathrm{scCO}_{2 \text { (PURE) }}$ and $\mathrm{scCO}_{2(\mathrm{MeOH})}$ (Table 3; Fig. 6). As the percentage of the co-solvent present increased, the strength of the wood slightly decreased. However, none of strength values for samples treated with $5.0 \mathrm{~mol} \%$ $\mathrm{scCO}_{2(\mathrm{MeOH})}$ decreased below the initial strength of the corresponding untreated wood sample; nonetheless it was lower than if the wood had just been treated with $\mathrm{scCO}_{2 \text { (PURE) }}$. The same trend was also apparent when looking at the Young's modulus (E) of the samples post treatment, indicating the samples had become more stiff.

Maple $(H)$ seems to be the exception to the rule (Fig. 7). It may be possible in the case of Maple $(H)$ that an extraction has taken place via the supercritical solvent stream, alongside the supercritical hydration. The Maple $(H)$ samples were collected as off-cuts from Oxford Violins, a violin makers and dealer who specialise in restoration. Restorers at Oxford Violins had stated that the off-cuts may contain consolidates from prior restoration work and that these were likely to include low molecular weight organic waxes or resins. As mentioned in the Introduction, $\mathrm{scCO}_{2}$ has a very low solvating ability with highly polar compounds. However, it is generally accepted that if a compound dissolves in hexane, a short chain hydrocarbon, then it will dissolve in $\mathrm{scCO}_{2}$, due to their similar solvating abilities [1]. This rule works well for low molar mass compounds such as organic waxes and resins. Increasing the concentration $\mathrm{MeOH}$ will have increased the level of extraction experienced by the Maple $(H)$, hence as the $\mathrm{MeOH}$ concentration increases, the strength of the maple decreases. Additional spectroscopic analyses of the historic Maple sample, pre and post treatment are being undertaken to identify the type of wax or resin that was extracted.

In general, the historic samples gave fewer significant results than the modern samples. However, the softwood Scots Pine $(H)$ gave significant results for all the supercritical treatments. This is very encouraging because Scots Pine $(H)$, had some of the lowest stabilised NMC of the whole sample set and gave no significant results for NMC. Given the low level NMC achieved by Scots Pine $(H)$, it could be proposed that the $\mathrm{scCO}_{2}$ is the responsible for the increased strength of the samples, rather than addition of water. $\mathrm{scCO}_{2}$ is known to swell polymer chain. The low viscosity and very low surface tension of $\mathrm{scCO}_{2}$ allows $\mathrm{CO}_{2}$ to penetrate the amorphous regions of the polymer matrix easily, causing swelling and sorption of $\mathrm{CO}_{2}$ [24]. Cellulose, hemicellulose and lignin form a series of complex matrix of organic polymers in wood. In the case of Scots Pine $(H)$ it is feasible that penetration of $\mathrm{scCO}_{2}$ into the organic amorphous polymer matrix in the wood samples occurred. This may cause the degraded cellulose, hemicellulose and lignin microfibril bundles

Table 3 A table to show the calculated mean bending strength (MOR) values of wood species that have been treated with $\mathrm{SCCO}_{2(\mathrm{PURE})}$ and $\mathrm{scCO}_{2(\mathrm{MeOH})}$ in comparison to the untreated oven-dried samples

\begin{tabular}{|c|c|c|c|c|}
\hline Wood & MOR oven-dried (MPa) & MOR sCCO ${ }_{2 \text { (PURE) }}(\mathrm{MPa})$ & 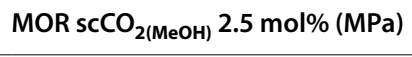 & 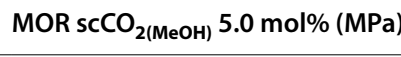 \\
\hline Maple (M) & 640 & 738 & 684 & 675 \\
\hline White Oak (M) & 528 & 715 & 659 & 625 \\
\hline Red Oak (M) & 521 & 743 & 717 & 600 \\
\hline Zebrano (M) & 791 & 970 & 958 & 900 \\
\hline Maple $(H)$ & 634 & 605 & 562 & 444 \\
\hline White Oak $(H)$ & 514 & 633 & 574 & 524 \\
\hline Scots Pine $(H)$ & 110 & 272 & 181 & 151 \\
\hline Keruing $(H)$ & 718 & 845 & 776 & 767 \\
\hline
\end{tabular}

Strength values have been stated to an accuracy of 3 significant figures 


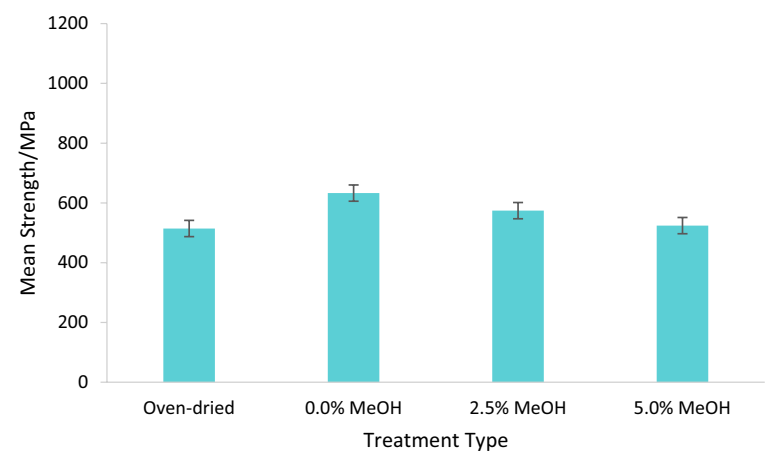

Fig. 6 A comparison of the mean strength values for White Oak $(H)$ samples pre and post treatment with $\mathrm{scCO}_{2(\mathrm{PURE})}$ or $\mathrm{sCCO}_{2(\mathrm{MeOH})}$. Each bar represents the overall mean from three independent sets of measurements \pm one standard error of the mean

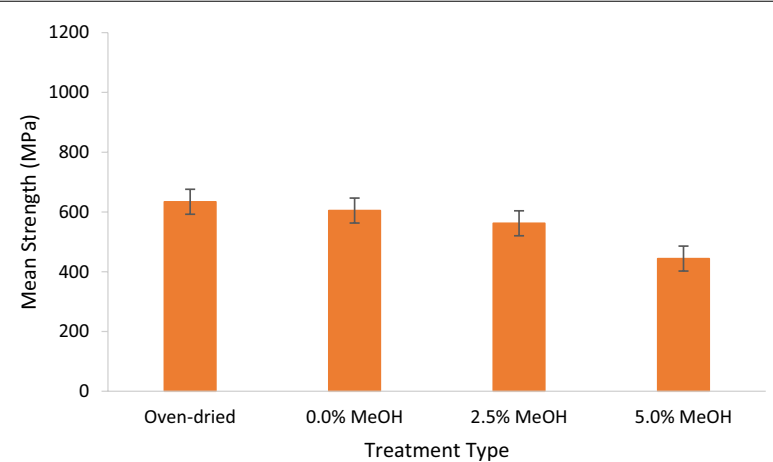

Fig. 7 A comparison of the mean strength values for Maple $(H)$ samples pre and post treatment with $\mathrm{scCO}_{2(\mathrm{PURE})}$ or $\mathrm{sCCO}_{2(\mathrm{MeOH})}$. Each bar represents the overall mean from three independent sets of measurements \pm one standard error of the mean

to swell and expand, subsequently stabilising the wood samples structure giving seemingly improved levels of strength.

For the duration of the supercritical experiments the pressure was held at $20 \mathrm{MPa}$, to ensure that the $\mathrm{scCO}_{2}$ was at a high density. It is therefore important that particular attention was paid to the pressurisation and venting of a SCF system in order to minimise any damage that could be caused to the samples. Having studied the internal pressure development and deformation during SCF impregnation on wood-based materials, Oberdorfer et al. [25] state that for solid wood, unless flow directions are restricted and pressure is rapidly increased, then the pressure differentials are not high enough to cause structural damage. However, it is inevitable that the historic wood samples will have been subjected to chemical and physical degradation over time, causing loss of structural integrity and the blocking of natural pathways including vessels, tyloses and pits. Due to the care taken depressurising the cell, it can be assumed that in general no additional damage was caused internally to the wood samples via unsafe depressurisation. However, Maple $(\mathrm{H})$ may again prove to be the exception to the rule here.

MOR data highlighted that increasing the overall NMC of wood, decreases its strength [17]. This is due to water forming cellulose-water bonds, thereby altering the cell wall structure and increasing its surface area. The decreasing strength values shown in Table 2 positively affirms the assumption that $\mathrm{scCO}_{2}$ is successfully hydrating the oven dried wood samples to a certain degree.

\section{DRIFT spectroscopy}

Prior to this analysis, preliminary studies on untreated and treated wood samples were performed by Attenuated Total Reflection Fourier Transform Infrared Absorption Spectroscopy (ATR-FTIR), Diffuse Reflectance Infrared Spectroscopy (DRIFT) and NIR-Raman spectroscopy (the results of these have not been reported in this study). In these studies, it was shown that in principle, it might be possible to quantify the degree of water content and other constituents of the wood, at least on a relative scale with the caveat that these analyses were performed on the surface of each wood sample. It is certainly plausible that the interior constitution may vary from this. It was also reported that the most promising technique was found to be DRIFT.

For the all the wood types that underwent DRIFT analysis the four individual samples all looked very similar on the spectra, Fig. 8 gives an example of the type of spectra produced. Here we can see that the broad band typically associated with $\mathrm{OH}$ stretches is observed at ca. $3490 \mathrm{~cm}^{-1}$ for the oven-dried sample. This band shifts towards lower wavenumbers for all the other samples examined. For the soaked sample the $\mathrm{OH}$ band is observed at ca. $3470 \mathrm{~cm}^{-1}$. As for all the wood spectra obtained in this study the bands observed in the region around $2900 \mathrm{~cm}^{-1}$ are associated with $\mathrm{CH}$ groups, as found in most of the organic molecular components. The bands in the region $2200-2300 \mathrm{~cm}^{-1}$ are associated with atmospheric and absorbed $\mathrm{CO}_{2}$. The other bands in the spectra are associated with the principal constituents of wood, in particular hemicellulose and lignins. The bands originating from cellulose are often partially hidden or limited in the fingerprint region (400-1800 $\mathrm{cm}^{-1}$ ) for DRIFT spectroscopy of wood due mainly to the physical arrangement of hemicellulose around the cellulose.

\section{O-H/C-H and O-H/"Cellulose" ratios}

The areas of the peaks at $\sim 3460$ and $2930 \mathrm{~cm}^{-1}$ can broadly be thought of as proportional to the amount of hydroxyl $\mathrm{OH}$ (i.e. including water) and $\mathrm{CH}$ groups respectively; the latter being a broad guide as to the 


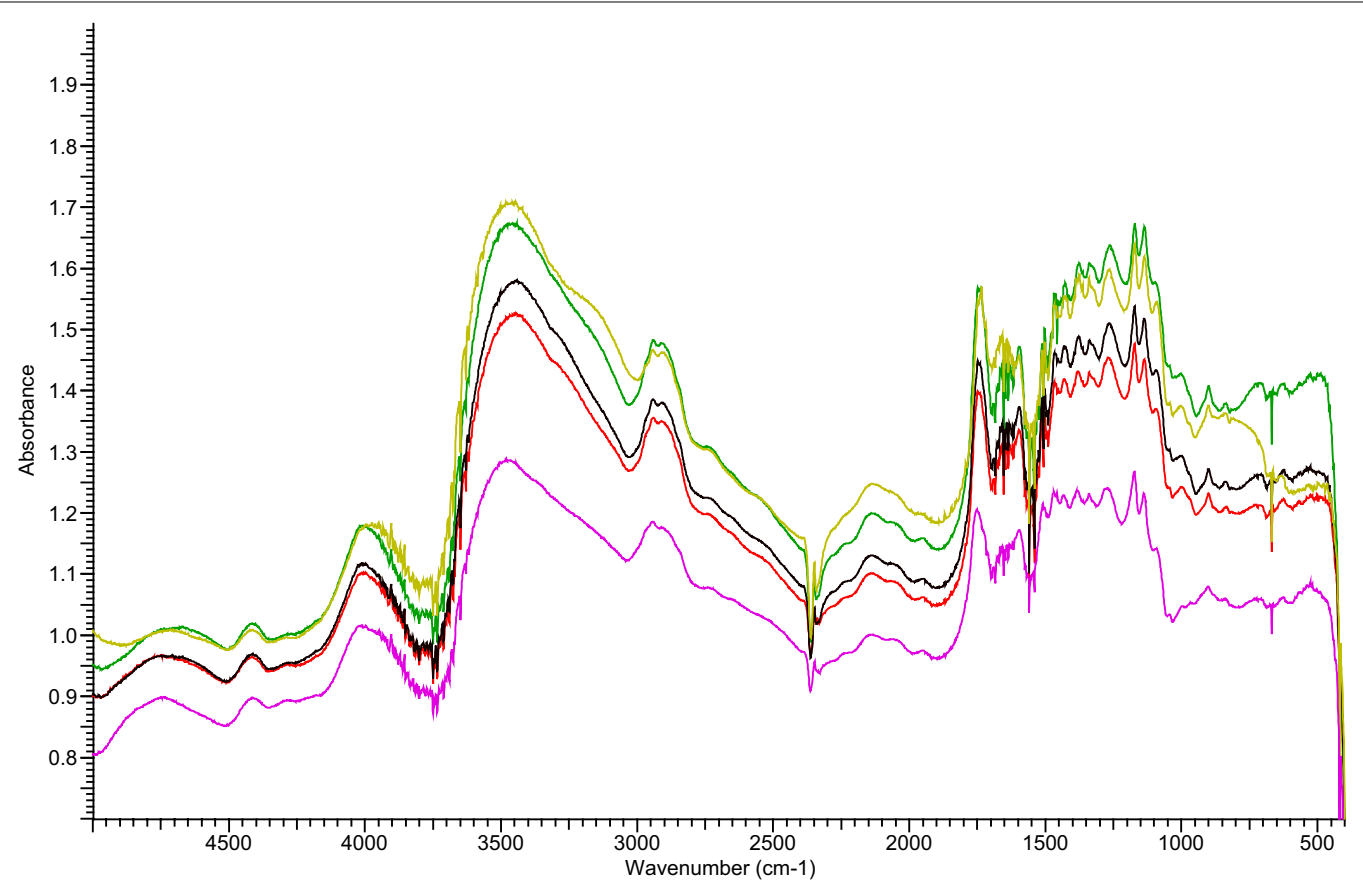

Fig. 8 DRIFT spectra of the different treated Red Oak (M) samples: Oven-dried (magenta), 2.5\% MeOH (red), 5.0\% MeOH (green), 10.0\% MeOH (black) and soaked (gold)

"quantity" of fibrous wood. The ratios of these areas were calculated for each of the samples and are plotted in Figs. 9 and 10 versus treatment and wood type respectively. As expected the soaked samples were observed to have a consistently higher $\mathrm{OH} / \mathrm{CH}$ ratio compared to the other samples; in contrast, the oven-dried samples have the lowest ratio for each wood. The other samples seem to follow the general trend of increasing ratio

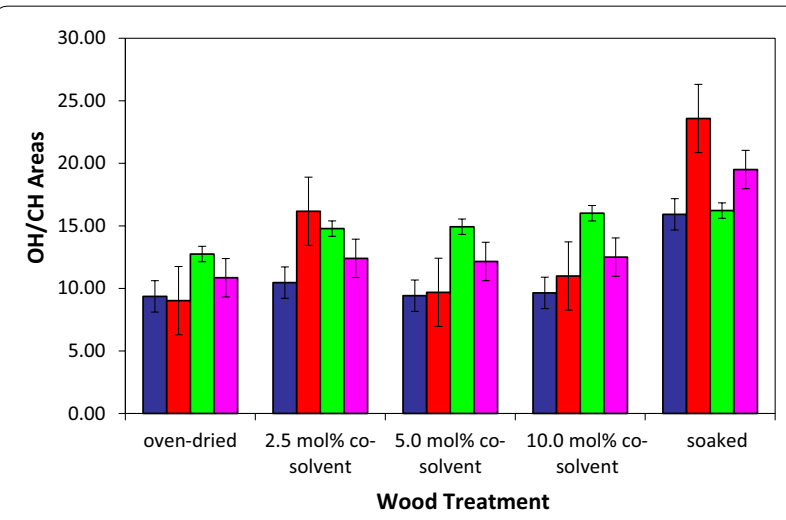

Fig. $9 \mathrm{OH} / \mathrm{CH}$ peak areas (around 3460 and $2930 \mathrm{~cm}^{-1}$ respectively) in DRIFT spectra obtained for Maple (blue), White Oak (red), Zebrano (green) and Red Oak (magenta) having undergone the five different treatments: oven-dried, $2.5 \mathrm{~mol} \% \mathrm{MeOH}, 5.0 \mathrm{~mol} \% \mathrm{MeOH}, 10.0 \mathrm{~mol} \%$ $\mathrm{MeOH}$ and soaked. Each bar represents the overall mean from calculated ratio areas \pm one standard error of the mean with increasing co-solvent percentage but some outliers are noticed; in particular the ratio for sample $2.5 \mathrm{~mol} \%$ $\mathrm{MeOH}$ of White Oak seems anomalously high.

An alternative approach is to consider the band at $4020 \mathrm{~cm}^{-1}$ as representative of cellulose and hemicellulose levels and calculate the peak area ratio of hydroxyls (around $3460 \mathrm{~cm}^{-1}$ ) relative to this, as depicted in Figs. 11 and 12. As can be seen, there are some trends

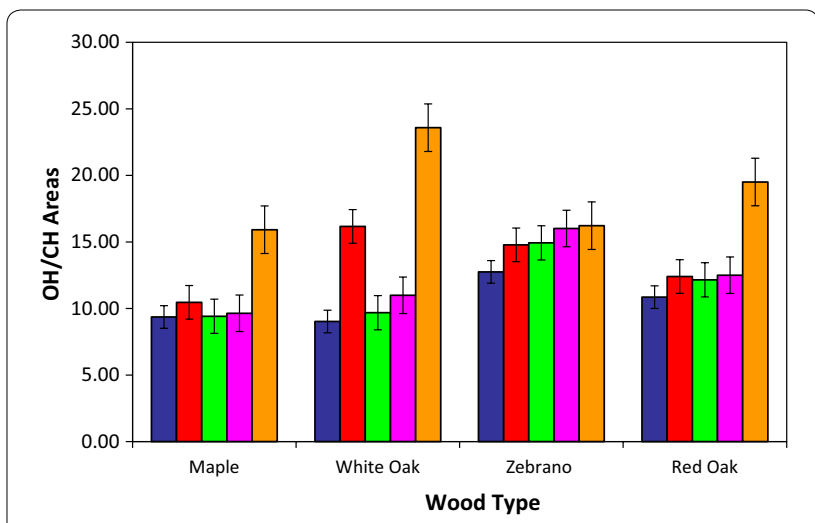

Fig. $10 \mathrm{OH} / \mathrm{CH}$ peak areas (around 3460 and $2930 \mathrm{~cm}^{-1}$ respectively) in DRIFT spectra obtained for Maple, White Oak, Zebrano and Red Oak having undergone the five different treatments: oven-dried (blue), $2.5 \mathrm{~mol} \% \mathrm{MeOH}$ (red), $5.0 \mathrm{~mol} \% \mathrm{MeOH}$ (green), $10.0 \mathrm{~mol} \%$ $\mathrm{MeOH}$ (magenta) and soaked (orange). Each bar represents the overall mean from calculated ratio areas \pm one standard error of the mean 
similar to those seen for the $\mathrm{OH} / \mathrm{CH}$ ratio data but again there are some anomalous cases.

\section{Other features}

It may be noted that the spectra have features at above $4000 \mathrm{~cm}^{-1}$, shoulders in the band at $3600 \mathrm{~cm}^{-1}$ and features in the $1900-2200 \mathrm{~cm}^{-1}$ region as well as a complex series of peaks in the fingerprint region. These are related to the detailed composition and physical state of the woods and would provide further information for the characterisation. Likewise, it can be seen that there is an apparent shift in the baseline level of the samples with treatment. This is associated with the general reflectivity and roughness of the surfaces and is again a characteristic

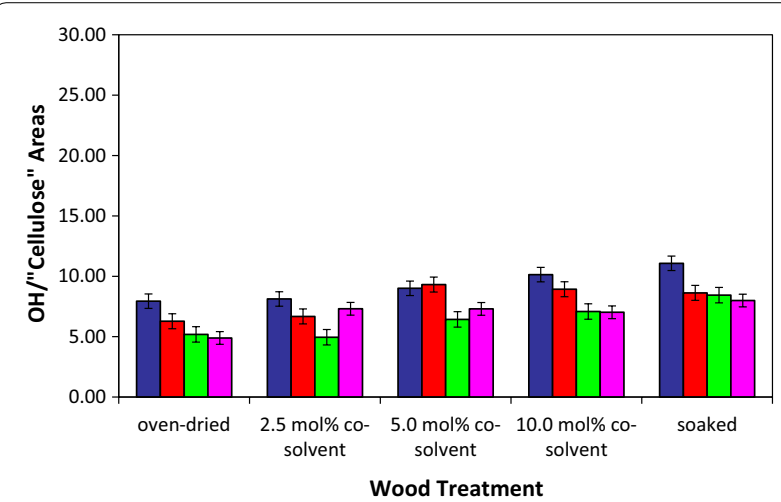

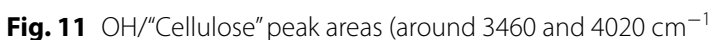
respectively) in DRIFT spectra obtained for Maple (blue), White Oak (red), Zebrano (green) and Red Oak (magenta) having undergone the five different treatments: oven-dried, $2.5 \mathrm{~mol} \% \mathrm{MeOH}, 5.0 \mathrm{~mol} \%$ $\mathrm{MeOH}, 10.0 \mathrm{~mol} \% \mathrm{MeOH}$ and soaked. Each bar represents the overall mean from calculated ratio areas \pm one standard error of the mean

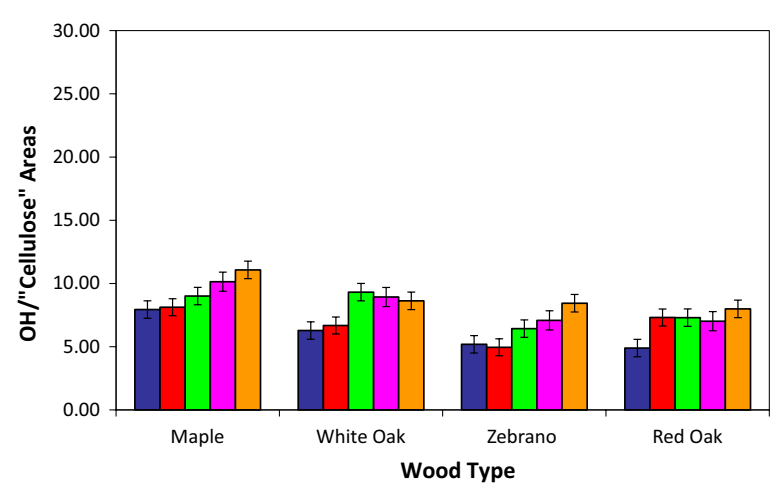

Fig. $12 \mathrm{OH} /$ /Cellulose" peak areas (around 3460 and $4020 \mathrm{~cm}^{-1}$ respectively) in DRIFT spectra obtained for Maple, White Oak, Zebrano and Red Oak having undergone the five different treatments: ovendried (blue), $2.5 \mathrm{~mol} \% \mathrm{MeOH}$ (red), $5.0 \mathrm{~mol} \% \mathrm{MeOH}$ (green), $10.0 \mathrm{~mol} \%$ $\mathrm{MeOH}$ (magenta) and soaked (orange). Each bar represents the overall mean from calculated ratio areas \pm one standard error of the mean of their nature. It is apparent that treatment of the woods affects the surface physically.

\section{Conclusions}

A general trend is observed when looking at the hydration data; increasing the concentration of $\mathrm{MeOH}$, increases the levels of NMC achieved by all the wood species in the sample set. It is suggested that hardwoods are more consistent in their ability to retain water, therefore concluding that wood type rather than wood age is more of an influencing factor on the absorbance levels of water. It is most likely that the impregnation and subsequent absorption of water into the wood matrix is influenced by a combination of macrostructural and microstructural features, which can vary between the individual wood samples.

The mean strength data has shown that the wood samples maintain or increase in strength after treatment with $\mathrm{scCO}_{2}$. The strength data suggests that a "happy medium" should be found between co-solvent addition and concentration, the levels of hydration achieved and the strength maintained or increased by the wood species, it also suggests that there may not be one supercritical treatment suitable for each wood species. The DRIFT spectroscopy studies were deemed to be reasonably successful with trends being identified. The calculated $\mathrm{OH} /$ $\mathrm{CH}$ and $\mathrm{OH} /$ "cellulose" ratios gave insight as to the possible interactions associated with the hydroxyl groups and the fibrous wood constituents. These ratios also gave supporting evidence for relationship between co-solvent concentration and NMC.

Currently, preventative methods are used when dealing with dry wood. These mainly involve controlling the environment in which the wood samples are kept, thus appealing to their hygroscopic nature. However, the interventive methodology developed here may be used as a complimentary treatment to be used alongside existing preventative methods; not replace them. The hydration levels achieved by the application of supercritical hydration may be maintained, and prolonged by the additional storage of the wood in a carefully controlled environment. Hence, wood samples may maintain an increased level of stabilisation for a longer period of time.

\footnotetext{
Abbreviations

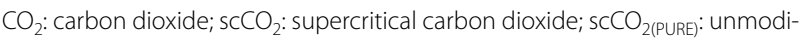
fied supercritical carbon dioxide; $\mathrm{scCO}_{2(\mathrm{MeOH})}$ : supercritical carbon dioxide modified with methanol; GRAS: generally regarded as safe; SCF: supercritical fluid; $T_{c}$ : critical temperature; $P_{c}$ : critical pressure; $\mathrm{MeOH}$ : methanol; $\mathrm{EtOH}$ : ethanol; $\mathrm{H}$ : historic; $M$ : modern; $\mathrm{H}_{2} \mathrm{O}$ : water; $\mathrm{OH}$ : oxygen hydrogen bond; $\mathrm{CH}$ : carbon hydrogen bond; NMC: normalised moisture content; MOR: Modulus of Rupture; E: Young's modulus; a: width; b: height; P: force; w: displacement; $\delta$ : delta; $g$ : gravitational constant; I: second moment of area; L: distance between two points; a: level of significance; ATR-FTIR: Attenuated Total Reflection
} 
Fourier Transform Infrared Absorption spectroscopy; DRIFT: Diffuse Reflectance Infrared spectroscopy.

\section{Authors' contributions}

GH designed the study and drafted the manuscript. GH carried out all experimental and analytical work (excluding work acknowledged by Chiralabs Ltd). PC participated in the design and coordination of the study and helped draft the manuscript. Both authors read and approved the final manuscript.

\section{Author details}

1 Department of Chemical Engineering, University of Birmingham, Edgbaston, Birmingham B15 2TT, UK. ${ }^{2}$ Department of Chemical Engineering, University of Wolverhampton, Wolverhampton, UK.

\section{Acknowledgements}

The authors wish to thank and acknowledge the contribution of Chiralabs Ltd (Oxford) in providing the spectroscopic analyses and interpretation.

\section{Competing interests}

The authors declare they have no competing interests.

\section{Availability of data}

No additional data is available as the $\mathrm{PhD}$ research project is in progress until May 2017.

Received: 6 October 2016 Accepted: 15 March 2017

Published online: 28 April 2017

\section{References}

1. Subramaniam B, Rajewski RA, Snavely K. Pharmaceutical processing with supercritical carbon dioxide. J Pharm Sci. 1997;86(8):885-90.

2. Clifford T. Fundamentals of supercritical fluids. Oxford: Oxford University Press; 1999.

3. Yesil-Celiktas O, Otto F, Parlar H. A comparative study of flavonoid contents and antioxidant activities of supercritical $\mathrm{CO}_{2}$ extracted pine barks grown in different regions of Turkey and Germany. Eur Food Res Technol. 2009;229(4):671-7.

4. Ekart MP, Bennett KL, Ekart SM, Gurdial GS, Liotta CL, Eckert CA. Cosolvent interactions in supercritical fluid solutions. AIChE J. 1993;39(2):235-48.

5. Iversen SB, Larsen T, Henriksen O, Felsvang K, editors. The world's first commercial supercritical wood treatment plant. Proceedings of the 6th International symposium on supercritical fluids, Versailles; 2003.

6. Acda M, Morrell J, Levien K. Supercritical fluid impregnation of selected wood species with tebuconazole. Wood Sci Technol. 2001;35(1-2):127-36.

7. Morrell J, Levien K, Sahle Demessie E, Kumar S, Smith S, Barnes H. Treatment of wood using supercritical fluid processes. Proc Can Wood Preserv Assoc. 1993;14:6-25.

8. Tucker SC, Maddox MW. The effect of solvent density inhomogeneities on solute dynamics in supercritical fluids: a theoretical perspective. J Phys Chem B. 1998;102(14):2437-53.
9. Schneider PF, Levien KL, Morrell JJ. Effect of wood characteristics on pressure responses during supercritical carbon dioxide treatment. Wood Fiber Sci. 2006;38(4):660-71.

10. Lenth CA, Kamke FA. Equilibrium moisture content of wood in high-temperature pressurized environments. Wood Fiber Sci. 2007;33(1):104-18.

11. Schneider PF, Morrell JJ, Levien KL. Internal pressure development during supercritical fluid impregnation of wood. Wood Fiber Sci. 2007;37(3):413-23.

12. Tello H, Unger A. Liquid and supercritical carbon dioxide as a cleaning and decontamination agent for ethnographic materials and objects. A Chronology of Middle Missouri Plains Village Sites; 2010. p. 35.

13. Sousa M, Melo MJ, Casimiro T, Aguiar-Ricardo A. The art of $\mathrm{CO}_{2}$ for art conservation: a green approach to antique textile cleaning. Green Chem. 2007;9(9):943-7.

14. Français É, Perrut M, Brandt A-C. Deacidification: Mass reinforcement of acidic and fragile papers with supercritical fluids. Conservation: a changing science balance sheet and outlooks. Proceedings of the 3rd international ARSAG Study Days. Paris: ARSAG; 1997. p. 131-40.

15. Kang SM, Unger A, Morrell JJ. The effect of supercritical carbon dioxide extraction on color retention and pesticide reduction of wooden artifacts. J Am Inst Conserv. 2004;43(2):151-60.

16. Tello H. Investigations on super fluid extraction (SFE) with carbon dioxide on ethnological materials and objects contaminated with pesticides; 2006.

17. The structure and mechanical behaviour of wood. 2008. http://www. doitpoms.ac.uk/tlplib/wood/printall.php.

18. Pandey KK. A study of chemical structure of soft and hardwood and wood polymers by FTIR spectroscopy. J Appl Polym Sci. 1999:71(12):1969-75.

19. Lalanne P, Tassaing T, Danten Y, Cansell F, Tucker SC, Besnard M. CO $\mathrm{CO}_{2}$-ethanol interaction studied by vibrational spectroscopy in supercritical $\mathrm{CO}_{2}$. J Phys Chem A. 2004;108(14):2617-24

20. Knapic S, Tavares F, Pereira H. Heartwood and sapwood variation in Acacia melanoxylon R. Br. trees in Portugal. Forestry. 2006;79(4):371-80.

21. Santos RB, Capanema EA, Balakshin MY, Chang HM, Jameel H. Lignin structural variation in hardwood species. J Agric Food Chem. 2012;60(19):4923-30

22. Rowell RM. Handbook of wood chemistry and wood composites. Boca Raton: CRC Press; 2012.

23. Gerhards CC. Effect of moisture content and temperature on the mechanical properties of wood: an analysis of immediate effects. Wood Fibre Sci. 1982;14(1):4-36.

24. Üzer S, Akman U, Hortaçsu Ö. Polymer swelling and impregnation using supercritical $\mathrm{CO}_{2}$ : a model-component study towards producing controlled-release drugs. J Supercrit Fluids. 2006;38(1):119-28.

25. Oberdorfer G, Leichti RJ, Morrell JJ. Deformation of wood-based material during supercritical carbon dioxide treatment. Wood Fiber Sci. 2007;36(4):511-9.

\section{Submit your manuscript to a SpringerOpen ${ }^{\circ}$ journal and benefit from:}

- Convenient online submission

- Rigorous peer review

Immediate publication on acceptance

- Open access: articles freely available online

- High visibility within the field

- Retaining the copyright to your article

Submit your next manuscript at springeropen.com 